\title{
IMAGENS DA CHINA HOJE
}

\section{Maria da Glória M. Gohn}

\section{APRESENTAÇÃO}

A participação em um evento científico na China, em Julho de 1999, possibilitoume ter uma experiência cultural tão rica e diferenciada que optei, neste texto, abordar inicialmente o lugar onde estive e conheci, para depois tratar da conferência propriamente dita. Isso porque aprendi tanto na visita às cidades chinesas que esse conhecimento possibilitou-me entender melhor vários temas tratados na conferência sobre o "Futuro das Cidades Chinesas", patrocinada pelo Comitê de Desenvolvimento Urbano da Associação Internacional de Sociologia em conjunto com a Academia de Ciências Sociais de Xangai, e a sessão da Associação Americana de Sociologia que trata dos estudos orientais. A conferência foi coordenada pelo Prof. John Logan, da Universidade de Albany, NY, EUA, com a colaboração do Prof. Lu Hanlong, da Academia de Ciências Sociais de Xangai.

Cheguei em Xangai, na costa leste da China, três dias antes da conferência. Tive, assim, a oportunidade de conhecer, extra-oficialmente, um pouco da cidade, fora dos roteiros programados aos seus visitantes habituais. Após o término do evento realizei, juntamente com outros 27 participantes da conferência, uma visita a três outras cidades localizadas em três regiões diferentes da China, a saber: Guilin ao sul, Xi’an na região central-oeste; e Beijing, a capital do país, na região mais ao nordeste.

Para que este texto não seja apenas o relato/registro das impressões (e grandes emoções) que vi e vivi, selecionei alguns textos apresentados na conferência de Xangai como fonte de referência de dados as observações e análises, assim como pesquisei outros dados sobre a China na Enciclopédia Encarta 99 da Microsoft, e utilizei uma série de reportagens publicadas sobre a China na imprensa brasileira nos últimos meses, em função das comemorações pelos "50 Anos da Revolução Chinesa". 


\section{A CHINA QUE VI E CONHECI}

Fui à China pensando que estava indo conhecer um país socialista, em transição para algo que não estava bem claro, se ocidentalizando; na realidade, vejo agora, eu estava carregada de estereótipos que o imaginário ocidental desenvolveu sobre aquele país oriental, a saber: imagens com milhares de pessoas, todas vestidas iguais, muitas filas, tudo muito igual, ausência de lojas ou shoppings, sem livrarias, bancas de jornais, comunicações difíceis etc. Na verdade, dessas imagens e representações, só uma teve realidade: a da existência de muitas pessoas (sem os uniformes modelo maoístas ou as filas). Um bilhão e quase trezentos milhões de pessoas é algo assustador e por mais que a China tenha um território vasto, e que a maioria das pessoas ainda esteja no campo, a concentração dessas pessoas nas cidades não se faz de forma proporcional. Alguns centros, como Xangai, tem atraído milhares de migrantes diariamente. O crescimento da população nos últimos anos é algo impressionante. Segundo dados oficiais, em 1993 a população do país era de 1.177.884.537 sendo 28\% na zona urbana e 72\% na rural. Em 1998, essa cifra já era de 1.256 .000 .000 e correspondia a $20 \%$ da população mundial. Para 2050 a projeção é de 1.478.000.000. Em algumas cidades, como Xangai, a população do campo e da cidade já se eqüivalem em termos percentuais. Em 1995 , $59 \%$ da população estava em atividades agricolas e pesca, $22 \%$ na industria e outros, e $14 \%$ no comércio.

A China que conheci (um pouco) é um país de tradição milenar, com uma cultura fantástica que se impõe e se sobrepõe a qualquer regime ou grupo político. É interessante ter presente alguns fatos e dados históricos importantes para entendermos melhor a China (farei isso na nota abaixo para não interromper a seqüência deste texto).

Quanto a cidade socialista/comunista que pensava encontrar, o que vi foram cidades chinesas, com milhares de anos de história, sendo apenas os últimos cinqüenta anos ligados à história do socialismo. Certamente que o modelo político existente se faz presente, no planejamento, na centralização e no controle da maioria das atividades econômicas e políticas; na imprensa e nos noticiários da televisão (os transmitidos em inglês destacam basicamente a situação e os conflitos de outros países, principalmente da vizinhança, como o conflito que estava havendo com Taiwan). A presença maior do Estado (leia-se PCC- Partido Comunista Chinês), está nas normas, não tanto em edificações ou guardas/policiais (que 
praticamente inexistem nas ruas, exceto na Praça Celestial em Beijing onde a presença de ícones simbólicos do socialismo é forte). Nos grandes out-doors existentes nos locais públicos, apenas na Praça do Povo em Xangai observa-se a presença estatal, com reportagens e entrevistas sobre questões que envolvem políticas locais. A maioria dos out-doors é de caráter comercial (embora possamos ter confundido alguns deles como meras propagandas comerciais pois, por não entendermos seus dizeres, fizemos a leitura pelas suas imagens).

Nas informações que obtive com as guias que monitoraram a nossa visita, apenas 6\% da população é filiada ao Partido Comunista. Entretanto, considerando o tamanho de sua população, isso dá uma cifra de algo perto de 78 milhões de pessoas. Quase a metade da população brasileira!

Todos os estudos demonstram o grande fluxo de migração do campo para a cidade. Ou seja, a urbanização está se acelerando. E o campo também está se transformando: de um lado observa-se que a produtividade agrícola nunca foi tão alta. "Milhões de famílias de trabalhadores rurais florecem com o aprendizado de técnicas de cultivo intensivo de produtos para mercados específicos, tanto das cidades como quanto locais rurais. Nessas famílias já há membros trabalhando em empreendimentos na comunidade (Fortune Américas, 1999:06)."De outro lado, em muitas aldeias as tradicionais comunas estão se dissolvendo e com elas desaparecem os fundos públicos que garantiam condições mínimas de saúde, educação, habitação e aposentadoria. Os "médicos descalços", enfermeiros que propiciavam atendimento rudimentar, também desaparecem, assim como as escolas passam a cobrar taxas. A flexibilização do controle estatal presente na nova etapa do modelo chinês de desenvolvimento tem levado à migração, milhares de chineses, do campo para as cidades, em busca de trabalho e/ou melhores condições de vida; só os mais velhos e as mulheres e as crianças (num primeiro momento) permanecem no campo. Entre os jovens, os homens dirigem-se basicamente para a construção civil, as mulheres para as fábricas ou trabalho doméstico. Usualmente, num primeiro momento, o dinheiro que o migrante ganhou na cidade, retorna para o campo, para ajudar o sustento da família que lá ficou. Os moradores mais antigos das cidades culpam os novos migrantes pela onda de violência que tem assolado as grandes cidades.

Uma grande indagação: como será o futuro das cidades chinesas? Com a abertura política e comercial, o desenvolvimento atual do país está importando não apenas novas 
fábricas e tecnologia. Os problemas que globalização econômica geram no ocidente, de perda da qualidade de vida, desorganização do mercado de trabalho etc., já estão presentes também na China. Há pobres nas ruas (ainda que sejam raros nas áreas turísticas, e que o número de crianças pedindo ajuda nas ruas centrais seja pequeno), faltam moradias (há contingentes de pessoas vivendo em cubículos escuros em plena região central, perto dos hotéis antigos de Xangai, por exemplo); as condições de saneamento nas cidades são péssimas, os banheiros públicos são um perigo à saúde etc. Entretanto, as condições de moradia já eram ruins antes das reformas. Segundo Ya Ping Wang, a privatização e reformas na área da habitação foi um dos mais importantes elementos das reformas econômicas porque elas possibilitaram o desenvolvimento de um setor chave no conjunto da economia. Novos modelos de habitação surgiram nas cidades socialistas e regiões com diferentes padrões de moradia, destinadas a diferentes grupos sociais, um novo cenário urbano passou a dominar no modelo de desenvolvimento adotado no país nos anos 90.

As reformas trouxeram várias mudanças no país, especialmente após 1992. Wang (1999) afirma que embora antes das reformas a população urbana era, em geral, pobre, não havia grandes concentrações de pobres ou "favelas" nas maiores cidades chinesas. As reformas propiciaram dois fenômenos sociais: a emergência de grupos sociais e econômicos bem sucedidos, e uma grande concentração de pobres nas grandes cidades. Vou me deter na análise desses últimos. Há dois tipos de pobres nas cidades chinesas atualmente: os pobres oficiais- aqueles que nasceram na cidade ou têm a sua moradia oficializada na cidade. Essa categoria mora usualmente em habitações de aluguel sendo a maioria delas de propriedade estatal. Os pobres que habitam regiões deterioradas nas regiões centrais vivem a espera (e na esperança) de serem transferidos para os conjuntos populares construídos pelo governo. A propriedade do solo é sempre do Estado e, portanto, caso alguém seja dono de algum imóvel, ele é dono da edificação e tem o direito ao usufruto do terreno por 90 anos, não é dono portanto do terreno, que é sempre do poder público. Os "pobres oficiais" têm direito aos serviços sociais públicos, destacando-se a saúde e a escola para os filhos. Mas há outra categoria de pobres: os não oficiais, os migrantes do campo que se deslocam para as cidades, os ex-"trabalhadores/camponeses". Essa categoria desempenha um papel econômico importante, como parte fundamental na composição da mão-de-obra nas novas frentes de trabalho, principalmente na construção civil, mas eles não têm direito ao acesso à serviços gratuitos estatais pois estão fora de seu lugar de cadastramento de moradia, dado por seu local de nascimento. Seus filhos não têm acesso à escola ou aos serviços de saúde. Os planos de 
assistência pública destinam-se aos pobres oficiais. O Estado reconhece a crescente importância econômica dos migrantes, mas não os considera como residentes permanentes, e nega-lhes direitos de cidadania urbana. Em algumas cidades iniciou-se um movimento de flexibilização criando-se um "cartão azul", uma espécie de plano de integração gradual: o morador recebe um visto provisório por sete anos. Durante esse período não pode ter problemas com a justiça criminal, e deverá obedecer aos regulamentos do planejamento familiar existente. Após o período probatório, o indivíduo poderá se candidatar a ser um morador permanente na cidade para poder ter direito ao acesso aos serviços públicos.

Recentemente, um funcionário do Fundo das Nações Unidas para a Infância afirmou que o governo chinês começou a enfrentar a pobreza, a questão da saúde e alguns lados obscuros de sua sociedade: o tráfico de mulheres e crianças. O Banco Mundial estima que há cerca de 300 milhões de pessoas (quase um quarto da população), vivendo em situação de risco. Se considerarmos a população total chinesa, essa cifra ainda é inferior, em termos percentuais, a população pobre no Brasil. O próprio governo brasileiro reconhece a existência de mais de 30 milhões de pessoas naquelas condições ( correspondendo a cerca de $20 \%$ da população). O governo chinês admite a existência de 42 milhões de pessoas vivendo abaixo da linha de pobreza (perto de 5\% da população). Entretanto esse número era de 250 milhões quando as reformas econômicas se iniciaram, há vinte anos atrás (e a população total era bem menor). Disso se concluí que as reformas estão provocando uma grande desorganização na sociedade chinesa mas está havendo também várias melhorias, principalmente na renda. De fato, a renda per capita da China saltou de US\$ 195 em 1990 para US\$ 774 em 1998. A renda média anual de um fazendeiro hoje é de 2.162 yuan. Em 1949 era de 44 yuan. Os moradores das cidades ganham em média duas vezes mais que no campo, e 70\% da riqueza do país está nas cidades, numa proporção inversa de sua população (relembrando que $28 \%$ de sua população está na zona urbana e $72 \%$ na rural).Com isso o perfil dos consumidores têm mudado também. Entre as camadas médias, os objetos de desejo deixaram de ser as bicicletas e máquinas de costura dos anos 80 para serem as tvs, os refrigeradores e os computadores. Uma verdadeira revolução está se operando nos padrões de consumo das famílias chinesas. Elas gastam uma parcela pequena de sua renda com aluguel e serviços públicos, mas adquirem, freneticamente, eletrodomésticos. Entretanto, os analistas econômicos destacam a capacidade de poupança da família chinesa média: 16\% de sua renda. "A poupança só perde para a alimentação e está à frente do aluguél", destaca o Suplemento "Fortune Américas". 
Isso tudo nos leva a concluir que embora haja pobres no país, a renda não é o seu principal problema mas sim o acesso aos serviços públicos, a aposentadoria, aos direitos trabalhistas etc. Nas regiões mais pobres a educação e a saúde também andam mal: as verbas não são suficientes para o pagamento dos professores e os livros consomem grande parte do orçamento familiar. Resultado: muitas crianças não vão às escolas. A medicina preventiva está em crise porque os salários dos médicos estão muito baixos e isso é um desestímulo para a categoria permanecer naquelas regiões. Mas o governo tem investido em programas de instalação de sanitários e o uso de adubos químicos na zona rural (em substituição ao uso de dejetos humanos como fertilizantes), buscando melhorar as condições de higiene e saúde. O sal iodado está agora disponível à 80\% da população, combatendo o bócio e contribuindo para o desenvolvimento mental das crianças, além de ter caído os índices de mortalidade infantil na última década. Em certas Províncias o governo assumiu a liderança em alguns investimentos de peso em infra-estrutura, embora seus esforços maiores sejam infra-estrutura à produção como aeroportos e incentivos à exportação de produtos da indústria local.

Entretanto não basta que se delineie no quadro atual da China suas dificuldades e problemas, muitos deles similares aos que estão sendo vividos em muitas outras regiões do mundo globalizado. É preciso que se destaque os avanços que foram realizados nos últimos 50 anos, para que se possa avaliar as mudanças operadas. Na área da Educação, por exemplo, em 1949, 60\% da população chinesa era analfabeta. Hoje esse número não passa de 12\%. A China tinha 540 milhões de habitantes em 1949 e hoje tem 1.248 bilhões. Parte desse crescimento deve-se também a melhoria nas condições de saúde: a mortalidade infantil era 25\% em 1949 e hoje é 3\%; a expectativa de vida em 49 era de 35 anos, hoje é de 71 anos.

Os planos e as expectativas de desenvolvimento da China para os próximos anos são animadores e surpreendentes. Para alguns analistas, espera-se que em 2010 a economia do país cresça a 5,5\% ao ano, tenha uma renda per capita de 10 mil dólares ( hoje é de 774), já tenha construído seu "Vale do Silício", tenha 600 cidades em áreas rurais, aliviando a pressão nas poluídas megacidades atuais, e incorporando a população que hoje migra para as cidades. "Os altos índices de crescimento nos últimos anos, o promissor mercado consumidor, a mãode-obra barata, a proximidade aos tigres asiáticos em crise, o poderio nuclear e o sucesso da integração territorial sugerem que a China poderá vir a ser a potência do próximo milênio". (FOLHA, 1999) 
O que se destaca no momento são as reformas econômicas. Elas trouxeram novos códigos e expressões ao vocabulário chinês: competitividade, produtividade, ganhar dinheiro (o slongan "enriquecer é glorioso" criado por Deng Xiaoping é a expressão emblemática da nova postura; uma outra é renascimento). Entretanto, na nova fase, assim como na globalização em outros regiões, o desemprego ronda. Ela não veio acompanhada da promessa de emprego para todos, slogan de tempos anteriores do PCC. Entre a população urbana, estimada em 409 milhões de habitantes, calcula-se que o desemprego atinge 3,1\% ( cerca de 12 milhões de pessoas). Na área rural as estatísticas não são precisas mas o governo estima em 100 milhões de camponeses que estariam vagando em busca de emprego.

"O desemprego e a ameaça de instabilidade social são, atualmente, a principal ameaça ao regime. Para enfrentar o desafio o governo transformou, em 98, o Ministério do Trabalho em Ministério do Trabalho e da Previdência Social."(FOLHA, 1999)

Entretanto, a globalização econômica deve ser vista de forma distinta na China porque lá o mercado sofre forte ingerência estatal e as condições das empresas privadas são diferentes das empresas estatais. As primeiras não têm as mesmas condições (ou regras de liberdade) para operarem de forma selvagem como o fazem no Ocidente. "Ainda é o governo chinês, por exemplo, que diz o que uma montadora pode fabricar, bem como o volume de produção e o preço. A GM, por exemplo, é obrigada a usar peças de fabricação local, 40\% em termos de valor esse ano (de 99) e 60\% no ano que vem. Embora esteja entrando com seus últimos avanços tecnológicos, a GM é limitada, pela legislação chinesa, a uma participação de apenas metade da joint venture.[..] e o governo chinês tenta algemar toda joint venture a um compromisso firme de exportação da produção."(Entrevista com Hu Mao Yuan, Suplemento Fortune das Américas, 1999: 10). Um dos problemas que as multinacionais enfrentam diz respeito a qualificação da mão-de-obra chinesa, tradicionalmente conhecida como baixa. Além disso não existe tradição no país de "atendimento do cliente com serviços de qualidade", e os fornecedores estão tendo que se adaptar a essa nova cultura, exigindo-se mudanças de posturas e atitudes. Para exportar a qualidade dos produtos têm que ser alta pois, no exterior, eles irão competir com outros produtos similares fabricados em distintas partes do mundo. Isso tem gerado aumento nos custos da produção.

As empresas estatais também são grandes, antiquadas, ineficientes, e exigem reformas difíceis de serem realizadas. Seu número é alto: 300 mil companhias. Calcula-se que cerca de um terço da mão-de-obra empregada nelas é excedente, ou seja, não necessária de 
fato. Mas o governo teme promover demissões em massa devido ao perigo de instabilidade social. Quem perde o emprego na área estatal o governo oferece um seguro equivalente a 80\% do salário, por dois anos. Existe ainda programas de demissões voluntárias para estimular os trabalhadores a irem para as empresas privadas.

Cada empresa estatal é administrada por um gerente/diretor e por um representante do Partido Comunista Chinês - que a supervisiona ( e em alguns casos é a mesma pessoa do diretor), além de um representante do sindicato. Segundo algumas pesquisas, as tensões são grandes pois cada vez mais é cobrado dos administradores a redução dos custos, aumento da eficiência etc. A maior fonte dos gastos são os salários e a assistência social aos empregados. A redução dos benefícios também está ocorrendo lá, assim como corte do staff de funcionários e aumento de suas responsabilidades. Estes fatos têm criado conflitos entre os administradores e os trabalhadores. Entretanto, durante o período que estive na China os jornais noticiaram várias vezes que o governo iria aumentar os salários dos funcionários públicos objetivando incrementar a demanda e o consumo interno. Isto porque seu índice de crescimento, que em passado recente já atingiu 11\%, caiu para 7,8\%; eles também estão com problemas com déficit orçamentários, apesar de possuírem superávit comercial, PIB de 960,9 milhões, reservas consideráveis, pouca dívida externa e uma inflação anual de apenas 0,8\%.

Objetivando estimular a produtividade dos trabalhadores o governo promoveu, recentemente, uma reforma adotando um sistema que é um misto de cooperativas onde os trabalhadores se tornam "donos" das empresas. Segundo a pesquisa citada acima, nas pequenas cidades e nos vilarejos o sistema tem tido algum sucesso. Mas elas têm gerado também vários problemas no equacionamento dos diferentes interesses e na adaptação das diferentes culturas locais (pois cada região tem a sua). As culturas locais são muito fortes, este é um dos pontos que o regime socialista soube ajudar a preservar/cultivar nas manifestações populares nos parques, teatros locais, museus e centros culturais.

Os mais velhos resistem a onda dos Mac Donald's, novos shopping centers, e comportamentos ocidentalizados. Os jovens são os que estão assimilando mais rapidamente as transformações. Eles são mais abertos, receptivos e se esforçam para interagir com os estrangeiros ocidentais. Muitos adolescentes e crianças nas ruas, quando vêem um ocidental, ficam felizes em pronunciarem algo como "Hai" ou "Olá". Seus pais também os incentivam a 
interagir com os estrangeiros. E quando algum jovem sabe um mínimo que seja da língua inglesa, ele logo quer ajudar o estrangeiro, indagando se precisa de algo ou se está procurando algo. Na realidade ele está querendo também exercitar o pouco que aprendeu e aproveitar a ocasião, tão rara, de usar a língua que aprendeu. Como sabemos, a língua oficial na China é o mandarim. Mas existe seis dialetos no país ( incluindo o tibeteano e o mongól), e mais 14 línguas minoritárias. Registre-se também que o mandarim é atualmente a língua mais falada no mundo: 885 milhões de pessoas a tem como língua usual ( o inglês vêm em segundo lugar com 322 milhões de falantes).

Um fato que consideramos relevante é a questão da religiosidade. Apesar da religião ter sido abolida oficialmente pela Revolução de 1949, e os dados estatísticos indicarem que em 1994, 69\% da população era composta de ateus e só $20 \%$ professarem as seitas tradicionais (confucionismo, taoísmo e budismo), o que se observa é que ela parece estar ainda muito presente no dia -a - dia das pessoas. Visitamos vários templos, a maioria budistas. O culto, a reverência, a devoção, é algo muito forte. A maioria das pessoas que lá estavam não pareciam "turistas". Segundo uma das guias de nossa visita, a religião hoje é livre, e cada um tem a sua. O budismo é muito praticado ( exceto a vertente do Dalai Lama, que é condenada), o confucionismo menos (embora sua pregação à ordem e o respeito às autoridades sejam valorizados); e o taoísmo ainda não é "bem visto pelo governo porque não seria muito bom para o povo". Na realidade o taoísmo foi o culto mais combatido como "a areia nos olhos do povo" nos dizeres de Mao Tsé-tung. Uma das explicações deve ser a liberdade de pensamento, e de expressão, que aquela seita (ou filosofia de vida) preconiza. Certamente que os mais ortodoxos vêem apenas "alienação da realidade" em todas essas religiões.

Embora as regras sobre o direito de professar, ou não, cultos religiosos tenham sido flexibilizadas, o controle sobre as seitas ainda existe. Em Julho de 99 a seita Fa Lun Gong foi proscrita pelo PCC sob o argumento que seu líder espiritual aproveitou da ingenuidade dos seus seguidores, e estava enriquecendo com as doações exigidas; a seita foi acusada também de promover a desorganização familiar e pessoal. Durante duas semanas o "Diário do Povo", jornal oficial do PCC, e outros diários redigidos em inglês ( voltados para a comunidade internacional) noticiaram "os crimes" daquele líder. Na realidade esse líder, que misturava budismo com exoterismo, pincelado de métodos alternativos de cura de doenças 
como o estresse etc., reuniu, em abril de 1999, 10 mil pessoas na porta do governo de Beijing pedindo o reconhecimento oficial da seita. O culto foi banido porque se tornou uma ameaça ao regime e desafiou as leis que proíbem grandes manifestações públicas. Segundo uma reportagem publicada em $1^{0}$ de Outubro pelo Correio Popular de Campinas, "Os chineses gozam de uma liberdade inédita para escolher seu estilo de vida e seu trabalho, mas a dissidência política pública é ferozmente castigada".

Os avanços na área de comunicações estão tornando débeis os controles do Estado sobre o que os chineses pensam, o governo já não se infiltra mais nos lares e nas comunidades locais, como no passado.

A flexibilização do caráter comunista do regime chinês, dado as reformas e a abertura para o Ocidente, tem desenvolvido um "socialismo com características chinesas" ou seja, uma economia aberta com sistema político fechado. Trata-se de uma mistura que une forte participação estatal na economia, setor privado financiado por capitais estrangeiros e as chamadas cooperativas (locais ou nacionais). Essas últimas tem grande articulação com o poder local e envolve a participação dos trabalhadores em sua gestão. Deve-se registrar que na China o capital estrangeiro é o principal acionador do novo desenvolvimento econômico, ao lado dos investimentos governamentais. Segundo dados publicados na Folha de São Paulo, em 1998 o país recebeu mais de US\$ 45 milhões, ficando atrás apenas do Reino Unido e dos EUA. É interessante assinalar que cerca de $80 \%$ dos investimentos externos provêm de chineses da diáspora, espalhados pelo mundo. Os países vizinhos são os maiores investidores na China. Em 1997 Hong Kong (antes da incorporação) investiu U\$ 20,6 bilhões de dólares; o Japão \$4,3; Taiwan \$ 3,3; EUA \$ 3,2; Singapura \$2,6; Coréia \$2,1; Reino Unido \$ 1,9; e Alemanha \$1,0. No total, os investimentos externos passaram de U\$ 3,4 bilhões em 1990 para U\$ 45, 6 em 1998. E nos primeiros seis meses de 1999, esses investimentos já estavam em 18, 6 bilhões de dólares ( dados suplemento Fortune Americas, 1999, p.2).

Há um ditado na China que diz: "quando o Ocidente vai mal, o Oriente vai bem". Seria interessante que os economistas realizassem estudos sobre essa questão e investigassem em que medida a crise em grande parte dos países ocidentais não deriva, também, da migração dos capitais para o Oriente. 
O modelo de desenvolvimento econômico que o regime político chinês tem adotado com as reformas merece uma discussão profunda pois ele poderá indicar pistas sobre o futuro do socialismo no século XXI. Dado a natureza deste texto, mais narrativo do que argumentativo/analítico, não vou dirigir a reflexão para essa direção mas registro apenas a necessidade do debate político sobre os caminhos da China. Para alguns, está havendo um retrocesso. Para outros, trata-se de um "capitalismo de estado"; outros o caracterizam como "socialismo de mercado", e outros ainda como "economia de mercado socialista". Alguns argumentam que o mercado "gera desigualdades, acumulação de mercadorias, o empobrecimento progressivo de um pólo da sociedade em função do enriquecimento do outro. O Socialismo propõe a igualdade". Essa posição é relativizada por Boron quando afirma "o socialismo e os mercados não se amam, mas talvez por um tempo sejam forçados a conviver". Sader já ameniza mais ainda dizendo:

"não devemos pensar que o socialismo é a sociedade sem classes, sem Estado, sem alienação. É uma transição e dentro dessa margem eu aceitaria pensar formas mercantis sobreviventes, mas com uma dinâmica tendencialmente superadora da lógica de mercado".

Já THERBORN é enfático:

\begin{abstract}
"devemos advertir que a democracia não sintetiza nosso ideal, embora seja o melhor que temos. A democracia não é o comunismo, tampouco o socialismo.[..] Resumindo, três pontos me parecem fundamentais: estabelecer a contradição intrínseca entre os princípios éticos e sociais do socialismo e do mercado como modelo de sociedade; reconhecer a eficiência, a racionalidade e a igualdade potencial do mercado como mecanismo de decisão; assumir que o controle e o planejamento democrático não são a solução mas um meio para resolver problemas".
\end{abstract}

Em suma, as posições estão postas. O que falta é um debate político apaixonado, mas renovado. Infelizmente quando algumas lideranças da esquerda brasileira se encontram, parece que estão mais preocupados em continuarem medindo forças sobre as diferenças do passado, entre quem deteria "a verdade" ou o "caminho certo", ao invés de buscarem entender o presente, resgatando o processo histórico mas preocupados com a busca de rumos para o futuro. E enquanto isso a China avança em direção ao futuro. La nave vá!

No novo cenário chinês várias forças de caráter ideológico têm sido acionadas, destacando-se: a abertura para o Ocidente, a busca de realização econômica, a educação científica e cultural do povo; mais recentemente passou haver o estímulo ao nacionalismo e o ressurgimento de valores tradicionais. A ideologia do socialismo passou a incluir a busca das 
raízes culturais da nação- a China milenar. Nesse resgate, a religião foi resgatada, sítios históricos foram descobertos, museus foram construídos, bens culturais passaram a ser preservados e o trabalho de artesãos - herdados de seus antepassados, passou a ser estimulado. A memória de uma das civilizações mais antigas do mundo passou a ser cultuada e o orgulho pelo passado restaurado. Essas diretrizes têm possibilitado a constituição de novas formas de nacionalismo, mais ricas e "sadias" porque fundamentam-se em valores estéticos e culturais. Talvez o "novo homem/mulher" a ser construído, enquanto ideal humano, passe por essas novas orientações. Na realidade esses processos iniciaram-se nos anos 80. Em 1986 o Partido Comunista elaborou um documento expondo suas decisões a respeito dos "Princípios orientadores para a construção de uma civilização espiritual socialista". O documento coloca as seguintes diretrizes como estratégicas para a modernização socialista chinesa:

\begin{abstract}
"tendo o desenvolvimento econômico como fulcro, conduzir com firmeza as reformas dos sistemas econômico e político, reforçar a construção a construção de uma civilização espiritual, coordenar os trabalhos os trabalhos e fazer com que eles se estimulem mutuamente.[..] A civilização espiritual socialista, que se orienta pelo marxismo, é uma característica importante de uma sociedade socialista.[..] a posição estratégica de construção da civilização espiritual socialista determina que esta deve promover a modernização socialista, e que deve fomentar a reforma em todos os sentidos, a abertura para os estrangeiros e a perseverança nos quatro princípios fundamentais. [...] encorajar uma parte das pessoas a enriquecer primeiro, sob o objetivo do enriquecimento humano".(1986: 1,2, 4 e 10
\end{abstract}

A China atual tem uma organização administrativa complexa. Ela possui 2.000 divisões administrativas, além de regiões autônomas como o Tibete e a Mongólia Interior (região localizada ao sul do país que tem esse mesmo nome, a Mongólia propriamente dita). Possui Províncias e três cidades controladas diretamente pelo governo central: Beijing, Xangai e Tianjin. O PCC introduziu recentemente uma experiência de eleições diretas para prefeitos em vilarejos rurais que tem sido considerada como bem sucedida e pode evoluir para um modelo de eleições mais amplas.

Desde 1997 está em curso um plano elaborado pelo falecido Deng Xiao-ping, de reunificar todo o território chinês sob o princípio: "um país, dois sistemas". Isso significa que o sistema econômico capitalista permanece intacto nas ex-colônias por 50 anos, mas o sistema político passa a ser administrado pelo governo chinês. Sabemos que Hong Kong (ex-colônia inglesa) foi incorporada à China em 1997 e Macau, ex- colônia portuguesa, será incorporada em 20 de Dezembro 1999. O mesmo não ocorre com Taiwan, região de conflitos desde 1949 quando o governo nacionalista chinês de Chiang Kai-Chek refugiou-se naquela ilha, após a tomada do poder por Mao Tsé-tung. Entretanto, para acelerar suas reformas pró-economia de 
mercado, a China precisa do investimento oferecido por Taiwan. E Taiwan necessita de mãode-obra mais barata e de novas fronteiras para se expandir. O diálogo entre os dois governos iniciou-se em 1990 e a China fez a proposta de ser a sede do poder político e a "ilha rebelde" manteria seu sistema capitalista com grau de autonomia. Taiwan resiste a essa forma de reunificação política impondo, como condição, a democratização completa da China comunista. A China ameaça invadir Taiwan por essa oposição e essa situação configura um dos principais focos de tensão na Ásia atual.

A seguir farei a caracterização das quatro cidades chinesas que visitei, relatando um pouco do que vi/aprendi de interessante.

\subsection{Xangai - O arcaico e o moderno}

1. Xangai é atualmente a maior cidade da China em termos populacionais (13 milhões na cidade e 15 milhões na região de sua metrópole). A região de Xangai é uma das mais urbanizadas da China. A distribuição de sua população entre as zonas urbana e rural é praticamente a mesma. É a mais desenvolvida em termos de investimento econômico / industrial ( representa 10\% do volume comercial do país, possui 15.000 empresas de manufaturas), é o maior porto da China e possui dois aeroportos internacionais. Ela é também a mais famosa cidade chinesa, pelo que representa na atualidade e pelo que foi no início deste século, ainda no período da China imperial. Xangai é hoje uma das chamadas cidades globais- como sabemos, essas cidades se destacam como grandes metrópoles não tanto em termos populacionais mas por serem grandes centros de serviços voltados para o fluxo das transações internacionais. Elas são sedes de grandes bancos, de escritórios das grandes companhias, possuem um número elevado de profissionais especialistas em mercado financeiro, grandes escritórios de advocacia, grandes firmas de importação/exportação etc. Em suma, são cidades "de poder" ou sede do poder do capital. O crescimento econômico de Xangai na última década foi expressivo; o aumentou foi maior após a integração de Hong Kong à China, em 1997. Volumes expressivos de capitais daquela antiga colônia inglesa passaram a ser investidos maciçamente em Xangai, principalmente no setor da construção civil.

Atualmente, toda Xangai está em construção/reconstrução. Há obras em todos os lugares e de todos os tipos. A cidade parece ser um grande canteiro de obras. Torres altíssimas 
em estilos modernos, envidraçadas, despontam em áreas urbanas novas, planejadas, como Pudong - um bairro criado em 1990 para abrigar novas empresas, hotéis cinco estrelas, grandes edifícios para serem escritórios comerciais e sedes de grandes bancos (há 33 só entre os estrangeiros). O Plano Urbano de Pudong contém 192 grandes prédios. Em Julho de 1999, 87 deles já estavam prontos e 105 se encontravam em construção. Cerca de 27.51 bilhões de dólares já foram investidos na área e já está contratado o investimento de outros 10.495 bilhões. Segundo a exposição feita pelo prefeito/administrador de Pudong, por ocasião do encerramento da Conferência sobre O Futuro das Cidades Chinesas, o dinheiro desses investimentos provém de Hong Kong (27.9\%), Japão (11.8\%), Estados Unidos (22\%), Canadá (1.02\%), Inglaterra (2.9\%), Singapura (3.05\%), Taiwan (2.18\%), e mais de 5.000 empresas domésticas (29.15\%). Há 320 companhias estrangeiras operando lá destacando-se : GM, Bell, Sharp, Intel, JVC, Dupont, Siemens, Panasonic, Citibank, Kodak, etc.

Há cinco colegges em Pudong, uma nova universidade está formação, além de 500 escolas ( entre as primárias e as vocacionais). Registre-se que na área da Educação a cidade de Xangai possui atualmente 39 colégios, uma grande universidade e 1.600 institutos de pesquisa. No conjunto da população de Xangai, as estatísticas oficiais destacam que hum milhão e quatrocentos mil pessoas são profissionais ou seja, possuem algum tipo de diploma ou estudo pós escola básica.

Foram construídos inúmeros conjuntos habitacionais em Pudong nos últimos cinco anos e eles se diferenciam pela camada social do usuário. Há desde conjuntos bem simples, semelhantes aos construídos pelas nossas companhias habitacionais- mas que impressionam pelo volume, altura e área de extensão que ocupam, aos conjuntos residenciais térreos, murados, de luxo, como um Alphaville paulista. Até um campo de golfe foi construído para que os investidores estrangeiros que lá habitam, ou transitam, sintam-se "em casa".

As regiões mais antigas de Xangai, onde se localizam hotéis do período prérevolução de 1949, gravitam atualmente ao redor da rua Huan Hai, o pólo comercial chique da cidade. Lá são encontrados edifícios antigos e renovados, assim como edifícios modernos recém construídos. Eles convivem ao lado de conjuntos de casas térreas e sobrados encortiçados. O hábito de dependurarem as roupas nas janelas ou num varal em plena calçada ( tal a falta de espaço nas moradias) dá um toque de completa excentricidade e revela a profunda segregação urbana que a nova etapa de crescimento econômico está gerando. Na 
própria rua Huan Hai há um shopping com lojas apenas das grandes grifes: Armani, Channel, Louis Vitton, Lalique etc. E até uma filial do grande magazine francês "Primtemps" foi aberta na cidade. Mas na rua atrás da Huan Hai, os cortiços e sobrados decadentes predominam. Mas tudo está em recostrução/renovação. Na semana que lá estive, um grande conjunto de sobrados foi demolido com uma escavadeira e rapidamente começou a se transformar em estacionamento. Provavelmente uma nova torre logo virá naquele lugar pois esta é a seqüência do processo de renovação urbana.

Nos últimos cinco anos foram inaugurados grandes obras culturais que já se tornaram marcos referencias arquitetônicos da cidade de Xangai como o Museu de Xangai e o teatro/ópera de Xangai, obra de arquitetos franceses, modelos da arquitetura contemporânea junto a Praça do Povo; um shopping center subterrâneo ( que se apresenta como o único do gênero no mundo), a primeira linha de metrô da cidade, uma grande torre/observatório com uma magnífica vista de toda cidade, construída à beira do rio, formando com o centro cultural local, um conjunto arquitetônico magnífico. Da fase de construções patrocinadas pelo governo socialista/comunista restam os grandes parques populares, e as grandes esculturas ao ar livre em homenagem ao homem e a mulher trabalhadora, em diferentes situações (marinheiros, por exemplo- ao longo da área da orla). Exaltam-se a força e a coragem dos trabalhadores; as esculturas são grandes e musculosas, ao contrário do tipo físico predominante entre as pessoas do povo que é magro, de estatura baixa e de constituição franzina. Restaram também os grandes conjuntos de habitações populares construídos ao longo das grandes avenidas, ou às margens das vias de acesso à cidade, ou na rota dos aeroportos. A maioria desses prédios está deteriorada e o único ponto de destaque são as pequenas áreas e quadras de lazer que alguns conjuntos possuem.

Para um ocidental- ainda que vivendo em cidades populosas, como São Paulo por exemplo, o número de pessoas nas ruas das grandes cidades chinesas, e em Xangai em particular, é o aspecto que mais impressiona num primeiro momento. Não se tratam de aglomerações apenas nas áreas centrais, ou nos bolsões comerciais. Há milhares de pessoas pela cidade toda. Parte da explicação é dada pelo problema de restrições do próprio espaço físico (a moradia é um dos mais graves problemas sociais e espaços exíguos são padrões usuais e não exceções). Outra parte pode ser explicada por um fator cultural: ficar ao ar livre, de cócoras, só observando, ou em pequenos agrupamentos- jogando cartas ou outros jogos, nas calçadas, ruas, parques e canteiros gramados que separam as pistas de uma avenida, é um comportamento comum que remonta aos tempos antigos. Uma outra parte se deve ao fato de 
que nem todo mundo trabalha (o que é algo diferente do desemprego-que certamente existe). Além de não haver trabalho para todos, os velhos são cuidados pela família com muita reverência, cuidar dos pais é obrigação dos filhos, portanto ter muitos filhos é uma garantia de velhice assegurada, seguindo uma tradição rural. Mas há na China desde 1980 a "lei do filho único"- um grande programa estatal de controle da natalidade que teria inibido o nascimento de quase 300 milhões de crianças. Na realidade a política do filho único nunca funcionou inteiramente, na zona rural, entre as minorias étnicas, nas categorias profissionais que exercem profissões de risco etc., o próprio governo que já "autorizava" a quebra do regulamento para aqueles casos, está planejando rever a lei e implementar uma nova política de métodos voluntários de controle da natalidade. É comum também as separações e novos casamentos- que significam novas famílias, novos filhos. Aliás, a festa de casamento é um acontecimento muito importante. As famílias poupam para este grande dia. Existem firmas especializadas para as noivas (locação do vestido e maquiagem). Os noivos também programam e escolhem com muita antecedência o dia de seu casamento. É comum, aos sábados e domingos, vermos da calçada de ruas comerciais, pela vitrine destas firmas/shoppings, dezenas de noivas já vestidas sendo maquiadas. Em Xangai esses shoppings são atrações turísticas que constam até dos livros e roteiros turísticos sobre os destaques culturais da cidade!

Nos postos de trabalho existentes no setor de serviço contratam-se cinco vezes mais o volume de pessoas realmente necessário. Mas o atendimento não é mais rápido ou mais eficiente por isso. Nos hotéis e nas lojas há "exércitos" de pessoas para atendimento de serviços ou tarefas bastante elementares. Mas, aparentemente, não há divisão de trabalho e nem especialização de funções. Ao contrário, há muita confusão que aumenta muito quando se trata de atender um estrangeiro que não fale um dos dialetos do chinês. Todos são muito solícitos, recebem treinamentos para que tratem bem os estrangeiros- vistos como aqueles que estariam ajudando o desenvolvimento do país. Mas apenas excepcionalmente encontramos alguém que fale ou entenda algumas palavras do inglês.

Os ocidentais são a minoria da minoria. A sensação é de sermos alienígenas e analfabetos pois não entendemos seus códigos lingüísticos e nem há informações escritas em inglês disponível nos lugares públicos. Aprendemos a exercitar outras formas de comunicação como a dos gestos e a do olhar (quando entramos nos restaurantes, por exemplo, na maioria deles os cardápios são apenas em chinês e eles não falam ou entendem o inglês. A saída é 
indicar um prato do cardápio afixado na porta- quando há fotos, ou algum que um outro consumidor já esteja saboreando. Mas nem sempre o que os olhos vêem corresponde ao que o paladar aceita). Exceto em Beijing, encontramos poucos turistas ocidentais nas quatro cidades que visitamos. A maioria dos turistas nas ruas são orientais ( segundo uma guia, eles são da Malásia, Filipinas, Japão, Korea, etc. ou da própria China).

O prof. John Logan (organizador da Conferência de Xangai) relatou que, quando esteve na China pela primeira vez, há dez anos atrás, não era possível a um estrangeiro usar cartão de crédito em Xangai, muito menos usar e-mail ou celulares (que não eram comuns naquela época nem no Ocidente). Havia muito pouco o que comprar nas lojas. Hoje, a situação é totalmente diferente. A própria imagem atual de Xangai está intimamente associada às compras. Ela é o maior shopping da China, em termos de oferta na produção e de vendas no comércio. A mão-de-obra custa pouco (o salário mínimo na China varia bastante nas diferentes regiões. Em Beijing é cerca de 250 yuans (US\$ 30); em Xangai a média é 50 dólares mas em alguns locais, como nos restaurantes de padrão internacional, pode atingir a U\$ 100; mas em algumas regiões, como Xinjiang, não passa de US\$20. Mas se o custo da mão-de-obra é barato, o custo de vida também o é.

O trânsito é um ponto a parte em toda China. Em Xangai o caos é maior ainda, em toda cidade: automóveis, ônibus, pedestres, ciclistas (centenas, formando um cenário exótico com seus chapéus típicos; e as mulheres usam vestidos de seda- produto muito barato lá); e riquixas modernos ( um tipo de veículo que é parte de uma bicicleta ou uma moto, com um pequeno carrinho acoplado atrás para transporte de pessoas (com dois bancos, como uma charrete com cobertura), ou com uma pequena carroceira para o transporte de carga. Todos disputam espaços de circulação em meio aos canteiros de obras. Os faróis de trânsito são poucos e resolvem em parte; é usual a presença de um guarda no meio da rua- em cruzamentos de grande fluxo, tentando controlar a confusão. Atravessar ruas e praças é uma operação arriscada e exige coragem. Mas se não a tivermos nunca sairemos do lugar. O interessante é que não se observa um número elevado de acidentes (batidas de carros ou atropelamentos) como seria de se esperar, aos olhos de um ocidental. Há uma lógica que eles dominam e que só após alguns dias percebemos um pouco. É quando nos soltamos e enfrentamos a luta que é andar no meio do caos. Existem também regras para reeducar os infratores: quem atropela alguém tem, como pena, que realizar serviço voluntário no trânsito, defronte a escolas e hospitais, ajudando a crianças e velhos atravessarem as ruas. Eles são 
reconhecidos porque têm de usarem uma tarja vermelha no braço, quando em serviço de reeducação.

Todos nós sabemos que na China a medicina tradicional, milenar, persiste e é eficiente. É muito comum vermos nas calçadas das ruas comerciais, mesas e cadeira do tipo das que são usadas pelos bares e choperias, onde médicos-práticos ouvem as pessoas, fazem perguntas, tocam pontos nodais do corpo dos pacientes que estão sendo relatando seus problemas, e receitam os remédios, os chás e as ervas. É usual também o serviço de medição da pressão arterial nas ruas. Segundo uma guia, os aposentados se dedicam a essas tarefas. Vários remédios já conhecidos da medicina tradicional são encontrados com muita facilidade (ao contrário dos remédios alopáticos, vendidos apenas nas poucas farmácias e com receitas). As ervas são encontradas nas barracas e quiosques nas ruas.

Em Xangai visitamos, além dos pontos destacados acima, mais dois lugares emblemáticos: o Memorial onde se realizou a primeira reunião que deu origem ao Partido Comunista Chinês, em 1921; e o Jardim Yuan. O primeiro é um marco histórico; é um prédio acoplando à edificação que contém a famosa sala onde ocorreram as primeiras reuniões do grupo liderado por Mao Tsé-tung (a reunião final em que foi assinada a carta de criação do partido ocorreu num pequeno barco, após a polícia ter invadido a casa e os manifestantes fugido para o barco). Na sede do Memorial há uma exposição que faz uma retrospectiva sobre a criação do partido e sobre a introdução das idéias socialistas na China. Destaca também a atuação do Dr. Sun Yat-sen na década dos anos 10 e nos anos 20, quando reconstrói o Koomitang, o Partido Nacionalista Chinês. Próximo do Memorial localiza-se a casa do Dr Sun, hoje um museu aberto à visitação pública, tombada como patrimônio da nação. No memorial há também uma retratação, em cera, dos fundadores do PC reunidos. Esta é a parte que desperta grandes emoções nos populares que visitam o museu pois é como se estivessem na presença do "Chairman Mao", como carinhosamente ele é apresentado aos estrangeiros. O Memorial tem também, como em outros museus do mundo, um pequena loja onde se adquirem bottons, carteirinha do Partido, fotos, o livro vermelho de Mao etc., a preços insignificantes. Pessoas de aparência bastante simples viajam dos quatro cantos da China para visitarem o Memorial, tiram fotos junto ao grande emblema da foice e do martelo- no hall de entrada do edifício, e compram o material da loja. 


\subsection{Guilin - Os mais belos cenários da China}

Guilin fica ao sul, região com cenários cinematográficos. Grandes montes, que chegam a formar pequenas cadeias montanhosas, sinuosas, e totalmente cobertos de vegetação alta se intercalam com vales - onde é cultivado o arroz e há grandes lagos. A população local vive da cultura do arroz e da pesca nos rios e lagos da região. A topografia local conta ainda com cavernas e sítios arqueológicos com vestígios das tribos primitivas que habitaram o planeta, muitos séculos antes de Cristo. Antigas tradições também são mantidas como a pesca noturna com o auxílio de uma ave que nada, o cormorão. O pescador amarra um barbante em seu pescoço e joga-o n’aguá. Os peixes pequenos ele os engole. Mas os grandes ficam presos no longo pescoço da ave. Quando isso ocorre, ele volta rápido ao barco/jangada do pescador que coloca-o de ponta-cabeça, aperta-o, e ele expele o peixe ( que poderá pesar quase um quilo). O cesto do pescador paulatinamente vai se enchendo porque a pobre ave, logo que se liberta do engasgo, volta para a água. E cada pescador trabalha com 4 ou 5 aves simultaneamente. Assisti, impressionada, a estas cenas frente-a frente, de um barco que se desloca toda noite pelo rio para mostrar aos turistas as cenas da pesca com o cormorão. (Não fui informada sobre nenhuma entidade ambientalista que protestasse contra a tortura àquelas aves).

Visitamos uma pequena comunidade de pescadores em Guilin. Três coisas se destacam: a pobreza local, as péssimas condições da moradia e de trabalho e a foto de Mao Tsé-tung na parede da maioria das casas e bodegas do vilarejo. Segundo uma guia de Guilin, entre as camadas mais pobres, Mao ainda é o grande líder, aquele que cuidou do povo. E ela concluiu

\footnotetext{
"naquela época havia mais solidariedade. Um ajudava o outro. Mao ensinava o povo a fazer isto. Agora não, acabou a solidariedade. Mesmo numa cidade pequena como Guilin, há roubos e crimes. O turista têm de ficar de olho na carteira e nas máquinas fotográficas".
}

É bastante comum na pequena vila que visitamos, casas com um só cômodo e uma grande porta, quase da largura de todo cômodo, a qual ficava totalmente aberta e voltada para a rua. Era possível observar tudo (ou o pouco) que eles possuíam: camas e sofás velhosonde sempre havia alguém dormindo; mesa rústica, bancos e um fogão de ferro. Eram geminadas e sem janelas. Mas o que mais chamava a atenção era: atividades de trabalho logo na entrada do pequeno cômodo/casa; mulheres teciam ou bordavam em grandes máquinas ou 
teares pré-históricos. Fabricavam ou bordavam finíssimos tecidos de seda. A única luz existente era a da rua. Algumas casas eram um misto de oficina de processar o trigo para se fazer a farinha, ou ainda pequenos estabelecimentos que vendiam comidas em grãos e guloseimas. Tudo com muita gente ao redor, crianças circulando e velhos dormindo nas camas. O odor era sempre de coisas emboloradas.

\subsection{Xi'an - a primeira capital da China}

Xi'an foi a primeira capital da China após a reunificação dos diferentes reinos que existiam na época. Ela é também a cidade das tumbas, túmulos e achados arqueológicos. Lá se localiza o que está sendo considerado a Oitava Maravilha da Terra. São os " Terracota Warriors", exemplares e vestígios de um grande templo construído para ser o mausoléu de um imperador. São esculturas do tamanho natural de um homem, em terracota, representando todas as patentes da época de um exército de guerreiros. Todas são diferentes e elas trazem, na cabeça, diferentes tipos de quépes que indicam as patentes dos militares existentes. O sítio arqueológico foi descoberto recentemente, em 1974, e casualmente, por um camponês que ao retirar a água do poço de sua casa, teve a surpresa de retirar também a escultura da cabeça de um guerreiro. Escavações foram realizadas no local e descobriu-se toda uma cidade, que deveria ser o mausoléu do então imperador, com as esculturas dos militares de seu exército, e seus cavalos. Diz a reconstituição da História que aquele sítio havia sido destruído por uma rebelião dos próprios camponeses, súditos e soldados do imperador, que derrubaram as portas da cidade/templo e destruíram as imagens. Mas algumas se mantiveram intactas ou com poucas quebras. E desde o ano da descoberta dos "warriors", o governo chinês tem patrocinado escavações na área. Já foram descobertas três outros sítios arqueológicos como o primeiro, todos próximos. O governo construiu um enorme edifício/museu ao redor dos achados, possibilitando aos visitantes ter uma das mais impressionantes visões/conhecimento/reconhecimento sobre a História do homem. Trata-se de uma História que ocorreu há dois mil anos atrás.

\subsection{Beijing - a capital administrativa e as memórias históricas}

Beijing é o centro administrativo nacional. Não tem o nervosismo de Xangai, há grandes avenidas, a cidade já passou por reestruturações e modernizações; as ruas e avenidas 
principais são largas e bem arborizadas, há grandes viadutos e no geral a arquitetura moderna predomina. Há problemas de trânsito na região central e falta de espaço para estacionar. Mas ela tem cravado em plena região central o maior símbolo da era dinástica que é a Cidade Proibida. Trata-se do grande palácio imperial, residência oficial da realeza até 1912, todo murado, onde o povo não tinha acesso e hoje é a maior atração turística local, seguida da visita ao mausoléu onde está enterrado Mao Tse-tung. As duas edificações são separadas pela Praça da Paz Celestial, a emblemática Tiananmen ( ou Praça do Povo), que ficou famosa na História contemporânea devido ao massacre de estudantes nas manifestações de protesto em 1989. Recentemente todo o piso da praça foi trocado; colocou-se grandes lajotões que comportam, cada um, duas pessoas em pé. A reforma foi calculada para a praça abrigar hum milhão de pessoas.

Do meu ponto de vista o símbolo cultural mais forte de Beijing não está dentro de sua área urbana, mas fora. Na realidade não é um símbolo de Beijing mas de toda a China, e de toda a humanidade: é a Grande Muralha da China. Construída antes de Cristo, possui seis mil quilômetros de extensão ( dá para ir e voltar de São Paulo à Belém do Pará). Ela pode ser observada via satélite e foi uma das poucas coisas que os astronautas identificaram a partir da Lua! Sinceramente, escalá-la, ainda que em alguns poucos metros, e avistar o panorama de cima, foi a realização de um antigo sonho. Lá do alto, olhando as montanhas e os muros que a acompanham, que parecem não ter fim, é inevitável pensarmos em duas coisas: naqueles que a construíram manualmente- em seu esforço e sacrifício; e no próprio sentido da vida, das nossas vidas.

\section{A CONFERÊNCIA SOBRE O FUTURO DAS CIDADES CHINESAS}

Já mencionei no início deste texto que a conferência foi patrocinada pela Academia Chinesa de Ciências Sociais, pelo Comitê 21 da Associação Internacional de Sociologia (sobre Desenvolvimento Urbano e Regional) e pela Associação Americana de Sociologia. O evento ocorreu em Xangai. Participaram da Conferência 117 pesquisadores sendo 35 de vários países do mundo e o restante da própria China. Vários expositores de universidades americanas e européias eram especialistas sobre temas relativos à China. Houve portanto a oportunidade de conhecer bastante sobre os problemas urbanos chineses dado o grande número de trabalhos apresentados (sempre com transparências ou tradução simultânea para o inglês quando os expositores não dominavam bem este idioma). Mas foi muito 
enfatizado, desde o início da conferência, a importância da presença no evento de pesquisadores não especialistas sobre a China porque com a globalização só é possível entender os problemas urbanos a partir de uma perspectiva comparativa, e as pesquisas sobre o desenvolvimento urbano- base para as políticas urbanas- necessitam atualmente de abordagem multidisciplinar. Portanto, comparar a China com realidades e problemas de outros países, e colher subsídios de especialistas de outras áreas do conhecimento, era um dos objetivos da conferência. Dentro desta perspectiva é que ocorreu minha participação.

O organizador da Conferência, John Logan, professor de Sociologia e Política Social na Universidade de Albany e diretor do Lewis Munford Center for Comparative Urban and Regional Research, fez a palestra de abertura da conferência. Ele tratou dos principais problemas das cidades chinesas na atualidade e fez um panorama geral dos trabalhos a serem debatidos. A seguir, farei um sumário dessa palestra pois ela contém uma síntese dos principais temas tratados na conferência. Ele enfatizou três grandes problemas que afetam a dinâmica das cidades chinesas na atualidade: a globalização, as migrações e o mercado. Isto porque, a atual política de abertura econômica inseriu a China no fluxo de transações do mercado mundial. E dada a rapidez dessas transformações nos últimos anos, em Xangai em particular, não dava para se evitar de falar sobre a globalização-embora estejamos já cansados de falar sobre ela nesta última década. A reforma do mercado na China tem tido características peculiares porque a globalização lá não se refere apenas a fluxo de capitais. Há também um fluxo de culturas.

O problema mais grave a ser enfrentado para o futuro refere-se ao tema da marginalização das grandes massas que estão sendo deslocadas do campo para as cidades. Como vão sobreviver nas cidades? Em que condições? Como poderão ser integrados (ou não)?Em que condições já estão vivendo atualmente? Na China a questão das migrações tem faces diferentes porque as identidades nativas locais são muito fortes e se manifestam na linguagem, na comida e nos costumes cotidianos. A interação, os casamentos e a própria dinâmica cotidiana geram problemas de confrontos entre culturas diferentes. As cidades estão passando a ser etnicamente divididas em grupos/áreas de migrantes. Os mongóis são muito diferentes dos cantonêses ou dos tibetanos etc. Como eles se relacionam com a cidade? A China urbana é hoje uma oportunidade de se aprender sobre as fontes, raízes e origem das diferenças, de todos os tipos. 
A maior desigualdade existente hoje na China não é a de renda propriamente dita mas do acesso aos itens fundamentais para a vivência/sobrevivência no urbano: casa/moradia, escola, saúde/saneamento etc. A reforma do mercado após a abertura têm agravado estas desigualdades. A moradia por exemplo é um bem e um recurso chave. Todos lutam por um espaço maior. O acesso para melhorar a moradia depende do tipo de trabalho das pessoas mas depende também de sua posição política e de sua posição social. A Educação também é um grande elemento de diferenciação. Poucos tem o grau universitário e ele confere grande status social. Em Xangai, segundo trabalho de um urbanista presente no Congresso, é possível observar zonas de segregação segundo os níveis educacionais.

O planejamento urbano das cidades é um desafio em si. Uma grande indagação refere-se a quais as conseqüências políticas da grande concentração de pessoas em determinadas áreas urbanas?. A necessidade de incorporar os indivíduos/cidadãos neste planejamento de forma participativa (e não apenas informativa, sobre o que será feito) parece ser uma solução para alguns mas ela passa pela tarefa de qualificação mínima destes cidadãos. E para tal necessita-se de investimentos na educação para além da alfabetização.

A família é uma das instituições mais tradicionais e uma mais fortes em toda China. Ela dá cobertura aos indivíduos a vida toda e não apenas até a idade adulta. Vários pesquisadores apresentaram na Conferência trabalhos a este respeito demonstrando que a situação de não emprego, ou desemprego, não tem gerado altos índices de violência e desagregação social devido ao tipo de estrutura familiar vigente. A família age como um anteparo. Entretanto, no processo atual, a globalização transformou a China na grande fábrica da manufatura mundial. A mão-de-obra empregada nas indústrias têxteis, ou nas confecções, é basicamente feminina. Embora essa inserção ocorra também via o trabalho terceirizado, que se realiza no espaço doméstico, o impacto do trabalho da mulher sobre a estrutura familiar tradicional é um dos desafios a ser pesquisado no futuro. Há várias questões em aberto tais como: quais são as novas redes sociais que estão sendo criadas para contrabalançar o impacto das mudanças? Como as culturas locais estão reagindo às transformações. A velocidade dos processos exige respostas rápidas ao nível do planejamento e órgãos locais; mas será que eles estão preparados para tal, considerando a prática anterior, da centralização predominante em todos os aspectos da vida socioeconômica e política? 


\section{2- Temas tratados na conferência}

As principais sessões da conferência abordaram os seguintes temas:

1. As transformações urbanas na China.

2. O desenvolvimento metropolitano no período de transformação na China.

3. A reestruturação legal e administrativa nas cidades chinesas.

4. Reforma do mercado e mudanças nas relações de classes.

5. Serviços e políticas públicas: a participação da comunidade.

6. Mudanças institucionais na política habitacional.

7. Migrações: marginalização, controle e estratégias de desenvolvimento.

8. Planejamento e Cidades Globais.

9. Cidade e turismo: as novas "bolhas" de lazer e entretenimento. Um novo conceito de turismo: o histórico-cultural e ecológico.

10. . Desigualdade, pobreza e vulnerabilidade.

11. . Diferenciação e segregação nas cidades chinesas.

12. . Estratégias de desenvolvimento urbano.

13. . Estudos comparativos de desenvolvimento urbano.

14. . Qualidade de vida dos migrantes nas cidades.

15. . Desenvolvimento regional das cidades globalizadas.

16. . Vida comunitária e satisfação com a vida.

17. . Perspectivas teóricas do desenvolvimento urbano na China.

18. . Relações sociais nas cidades globais. 
19. . Planejamento e desenvolvimento urbano na China.

20. . O impacto da economia chinesa na Ásia.

21. . Impactos da cidade no campo.

22. . Planejamento para o futuro das cidades: recursos hídricos e desenvolvimento sustentável.

23. . Cultura urbana e relações sociais de vizinhança.

Para encerrar, é difícil falar em conclusões após ter vivido experiências tão ricas e diversificadas. O que fica é uma certeza: nunca aprendi tanto em tão pouco tempo. Nunca vi (ou melhor, vivi) experiências tão significativas. Certamente levarei algum tempo para assimilar tudo. Este texto é apenas o relato do primeiro impacto, a descrição se mistura com as emoções que tendem a tomar conta das análises. A razão quer imperar e analisar friamente tudo o que viu, ou pode absorver, mas não consegue. Em muitas partes do texto os sentimentos guiam a narrativa. Espero que este seja um primeiro trabalho sobre a China, e que muitos outros apareça. Além deste texto, fotografei na viagem cerca de 200 lugares ou pessoas emblemáticas e espero, também, realizar uma exposição com esse material.

\section{REFERÊNCIAS}

BORÓN, Atílio. Os novos leviatãs e a polis democrática. In: , SADER, Eder, GENTILI, Pablo, BORÓN, Atílio. (Org.). Pós -neoliberalismo. Petrópolis : Vozes, 1999. p.174-175.

FOLHA de São Paulo, São Paulo, SP, 30 set. 1999.

FOLHA de São Paulo. São Paulo, SP, 15 out. 1999. Cadernos FOVEST 2000. p.3.

GITTINGS, John Gittings. China abre o jogo e vai à luta. O Estado de São Paulo, São Paulo, SP. 05 set. 1999. p.A2.

GOHN, Maria da Glória Marcondes. Educação não-formal e cultura política: impactos sobre o associativismo do terceiro setor. São Paulo : Cortez, 1999. (Coleção Questões da Nossa Época; v. 71).

LOGAN, John. Three challenges for the Chinese city : globalization, migration, and market reform. In: CONFERENCE ON THE FUTURE OF CHINESE CITIES : A RESEARCH 
AGENDA FOR THE $21^{\text {st }}$ Century. 1999, Xangai. [Proceedings...]. Xangai : [s.n.], 1999.

LOWY, Michel. Estado, democracia e alternativa socialista na era neoliberal. In: GENTILI, Pablo, SADER, Eder, BORÓN, Atílio (Org.). Pós-neoliberalismo. Petrópolis : Vozes, 1999. p.171.

PARTIDO COMUNISTA DA CHINA. Decisão do Comitê Central do Partido Comunista da China sobre os princípios orientadores para a construção de uma civilização espiritual socialista. Beijing : [s.n.], 1986.

THERBORN, Göran. As teorias do Estado e seus desafios no fim de século. In: GENTILI, Pablo, SADER, Eder, BORÓN, Atílio (Org.). Pós-neoliberalismo. Petrópolis : Vozes, 1999. p.179.

YA PING WANG. Housing reform and its impacts on the urban poor. In: Conference "The Future of Chineses Cities", 21,1999, Shanghai. [Proceedings...] Shanghai : Academy of Social Science ; ISA, 1999.

YIU-CHUNG WONG, CHE-PO CHAN. Corporativism, civil society and democratization in contemporary China. In: ANNUAL REUNION OF AMERICAN SOCIOLOGICAL

ASSOCIATION, 1999, Chicago. [Proceedings...]. Chicago : ASS, 1999. 